\title{
SEM analysis of PA38-T6 aluminum alloy thin-walled tubular specimen fatigue fracture, and comparison to surface replication results
}

\author{
Jan Seyda ${ }^{1,2 *}$, and Lukasz Pejkowski ${ }^{1}$ \\ ${ }^{1}$ UTP University of Science and Technology, Faculty of Mechanical Engineering, Kaliskiego 7, \\ 85-796 Bydgoszcz, Poland \\ ${ }^{2}$ UTP University of Science and Technology, Doctoral School UTP, Kaliskiego 7, \\ 85-796 Bydgoszcz, Poland
}

\begin{abstract}
The paper presents results of SEM analysis of fatigue fracture surface of thin-walled tubular specimen manufactured from PA38-T6 aluminum alloy. In the previous research specimens were subjected to multiaxial loadings. They were axial, torsional, in-phase, $90^{\circ}$ out-of-phase and asynchronous loadings. During the fatigue experiments, the process of initiation and development of cracks was tracked using the surface replication technique, using cellulose acetate thin foils. In the present work, SEM observations of fatigue fracture surface were conducted and compared to previously obtained data. It was confirmed, that the dominating mechanism of fatigue crack formation was the coalescence of small crack, regardless of loading type and level.
\end{abstract}

\section{Introduction}

Microscopic analysis of phenomena occurring in the material under fatigue loadings is an important issue, because the stages of initiation and propagation of small cracks take, in most cases, a significant part of the fatigue life [1]. Sometimes, the direction of the cracks on the macroscopic scale does not coincide with the direction of the small cracks [2]. The development of fatigue cracks may be different depending on the material and the loading case, and on the scale of observation: the crack can grow on the planes of maximum shear strain [1], the planes of maximum principal stress [3], or on the planes of maximum shear strain to some length, and then change the propagation direction [4]. It may be also observed that the small cracks can propagate independently [5], or can connect by the coalescence mechanism [6,7].

The study of the fatigue crack development mechanism, depending on the loading case and on the material, is important for the analysis of experimental results and the improvement of fatigue failure accumulation and fatigue life prediction models. These models are based on the critical plane [8], principal strains [9] or energy parameters [10].

\footnotetext{
* Corresponding author: jansey002@utp.edu.pl
} 
The present work presents the initial results of research, in which two techniques were used to analyze the development of fatigue cracks. The surface replication technique using the cellulose acetate tape was applied to observe the damage mechanism with regard to the subsequent stages of fatigue life. These stages are initiation and growth of small cracks, and development of the main crack. The replication technique can be used to track the changes on the outer specimens' surfaces only. The SEM fractography may be applied to observe the fatigue fracture of the specimen with much higher magnifications than those used to observe the replicas under the optical microscope. The research where these two techniques are applied together are sometimes conducted for other metallic alloys [11].

\section{Materials and Methods}

The research was conducted on thin-walled tubular specimens, manufactured from PA38-T6 (AW 6060-T6) aluminum alloy (Table 1). Table 2 presents basic mechanical properties, Young modulus $E, 0.2 \%$ offset yield stress $\sigma_{y 02}$, ultimate tensile strength $\sigma_{u}$ and corresponding strain $\varepsilon_{\sigma u}$, elastic Poisson ratio $v_{e}$, cyclic strength coefficient $K^{\prime}$ and cyclic strain hardening exponent $n$ ' The dimensions of the specimens are shown in Fig. 1. The specimens' surfaces were mirror-polished using different grades of diamond paste in order to remove all machining marks and scratches.

Specimens were subjected to fully reversed axial, torsional and $90^{\circ}$ out-of-phase sineshaped loadings. All tests were performed on Instron 8874 servohydraulic axial/torsional testing frame. Strains were measured and controlled using an Epsilon 3550 biaxial extensometer.

This work is a continuation of the research aimed to study the multiaxial fatigue of metallic alloys in the elastic-plastic strain range. In the previous papers, the influence of additional non-proportional hardening on the fatigue life was studied [12,13], the directions of initiation and growth of small cracks on the specimens' surfaces were observed [14], and, initially, the development of fatigue cracks during the fatigue tests using the replication technique was studied [15].

Table 1. Chemical composition of PA38-T6 aluminum alloy according to EN 573-3 standard

\begin{tabular}{|c|c|c|c|c|c|c|c|c|c|c|}
\hline Element & $\mathrm{Si}$ & $\mathrm{Fe}$ & $\mathrm{Cu}$ & $\mathrm{Mn}$ & $\mathrm{Mg}$ & $\mathrm{Cr}$ & $\mathrm{Zn}$ & $\mathrm{Ti}$ & Other & $\mathrm{Al}$ \\
\hline $\begin{array}{c}\text { Share in } \\
\text { \% }\end{array}$ & $0.3-0.6$ & $0.1-0.3$ & 0.1 & 0.1 & $0.35-0.6$ & 0.05 & 0.15 & 0.1 & 0.15 & Balance \\
\hline
\end{tabular}

Table 2. Basic mechanical properties of PA38-T6 aluminum alloy determined experimentally

\begin{tabular}{|c|c|c|c|c|c|c|}
\hline$E, \mathrm{GPa}$ & $\sigma_{y 02}, \mathrm{MPa}$ & $\sigma_{u}, \mathrm{MPa}$ & $\varepsilon_{\sigma_{u}}$, & $v_{e},-$ & $K^{\prime}, \mathrm{MPa}$ & $n^{\prime},-$ \\
\hline 68.3 & 191.5 & 229.1 & 0.094 & 0.35 & 288.1 & 0.051 \\
\hline
\end{tabular}

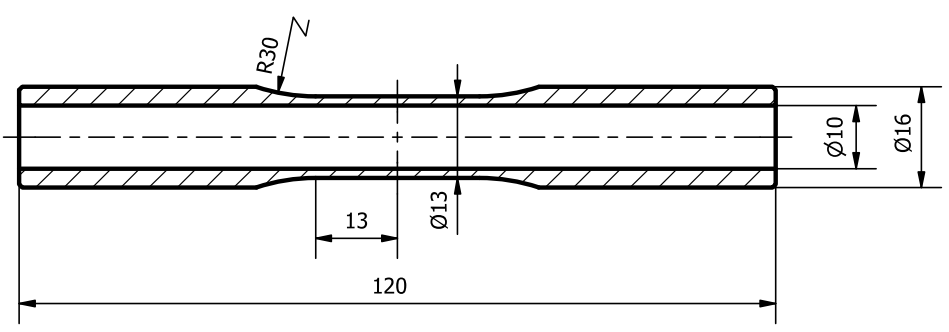

Fig. 1 Dimensions of PA38-T6 specimens, given in millimetres

The material used for specimen surface replication was $125 \mu \mathrm{m}$ thick cellulose acetate foil. The micro photographs were taken on a metallographic microscope Delta Optical MET- 
1000-TRF equipped with DLT-Cam PRO 12MP digital camera with dedicated image processing software DLTCamViewer.

The first test using a given loading case and level was always conducted in strain-control mode. Next, based on the recorded displacement history, the second test was performed in displacement-control mode. The fatigue tests were paused every $10 \%$ of expected fatigue life to take the replica on both sides of the specimen's gauge section. This technique was described more in-detail in [15]. In Fig. 2 the capabilities of replication are presented by comparison of a crack picture taken directly on the specimen's surface (a) and on the replica (b). The greatest advantage of this technique is the ability to track the history of cracks development.

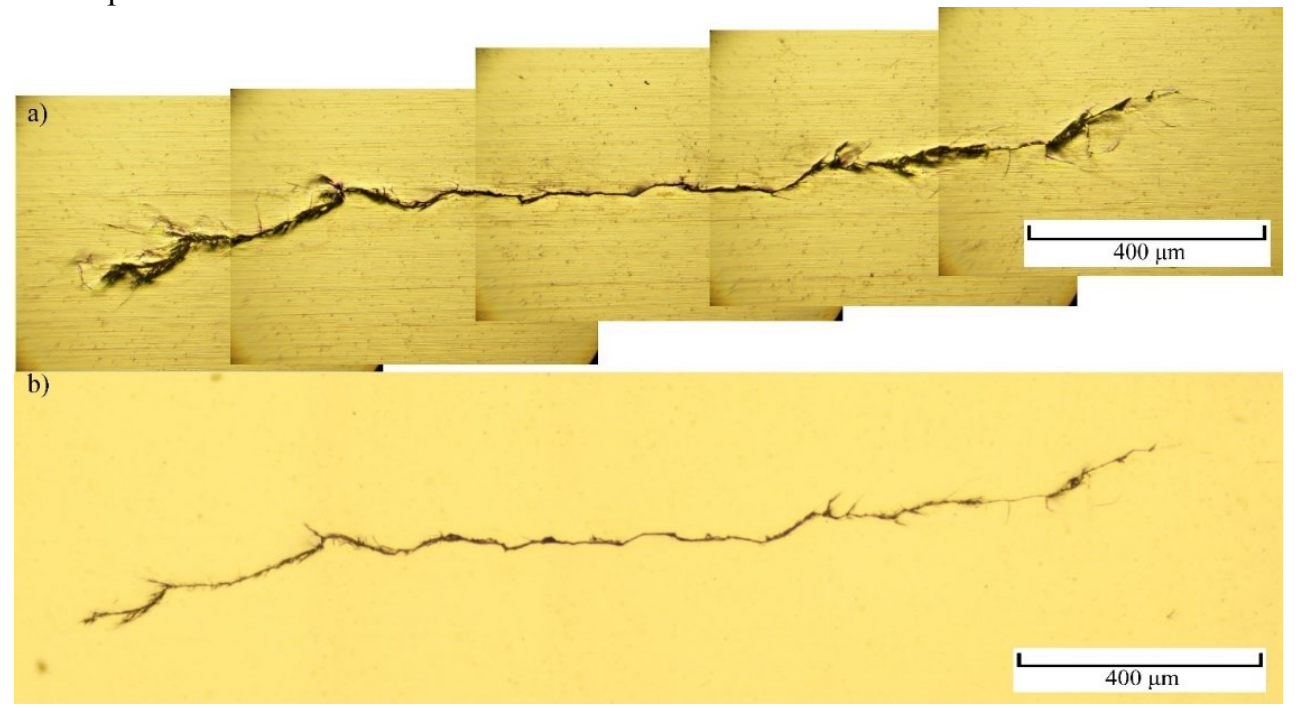

Fig. 2 Comparison of crack image taken from specimen (a) and from replica (b)

The SEM images were taken on JEOL 6480LV device, in which a dedicated working table was attached to grip the cylindric specimens vertically, with ability to tilt the specimen.

\section{Results and discission}

This work regards the results of tests performed using a single specimen, subjected to fully reversed axial loading, on the level of strain $\varepsilon=0.005$. This is the point marked with an arrow in Fig. 3. 


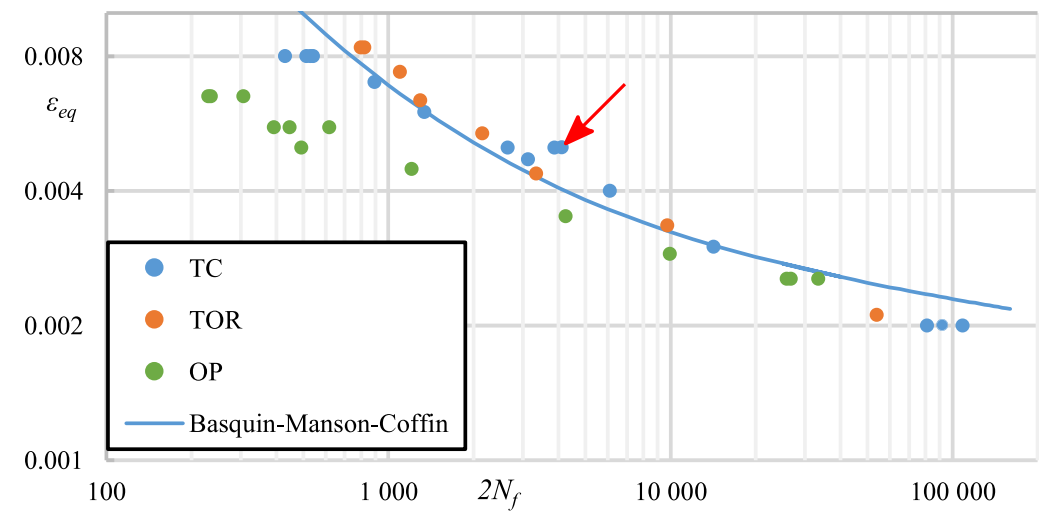

Fig. 3 Basquin-Manson-Coffin chart for PA38-T6 aluminum alloy for basic loading cases: $\mathrm{TC}$ - tension-compression, TOR - torsion, $\mathrm{OP}-90^{\circ}$ out-of-phase

The coalescence of small cracks was identified as a main crack development mechanism by the analysis of replicas, showing the cracking history. At the initial stage, the small cracks initiated and grew independently to small sizes. Next, they linked with nearby cracks forming a greater crack. The main crack development rate increased with the size of linked cracks.

The first small cracks were visible at, approximately, 50\% of fatigue life. In Fig. 4.a, many cracks, formed by the linkage of about 5 small cracks, can be seen. After the cracks reached the surface length of about $2 \mathrm{~mm}$, a rapid increase in the rate of damage process occurred, during which, drop of the axial force was recorded. Fig. 4.b presents the replica at the moment when the first notable decrease in the axial force value occurred. It took only $2 \%$ of fatigue life to the total fracture of the specimen.

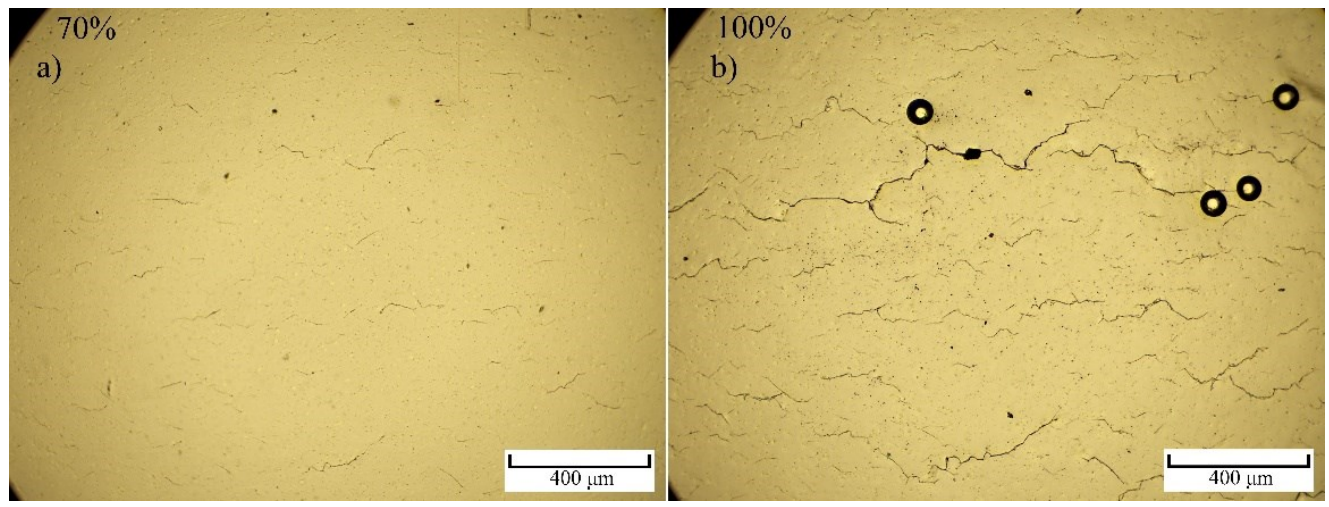

Fig. 4 The replicas' fragment presenting the origin of the main crack

Replication provides the information on the changes occurring on the outer surfaces of the specimens. The SEM fracture analysis, despite it is used after the experiment, provides the information on the phenomena taking please inside the material. Fig. 5 presents the fatigue fracture of specimen subjected to axial loading at $\varepsilon=0.005$, with marked fragments, which are discussed below.

The blue arrow in Fig. 5 points the area, in which, using the replication technique, the initiation of the main crack was identified. Multiple small cracks can be seen on a magnification of this fragment (Fig. 6). All origins were on the surface of the specimen. Next, they linked into one larger crack. Fatigue striations are also visible. The distance between striations increased with each loading cycle. The main fracture is not elliptic-shaped, but 
rather is a single front of interconnected cracks propagating deep into the specimen's material.

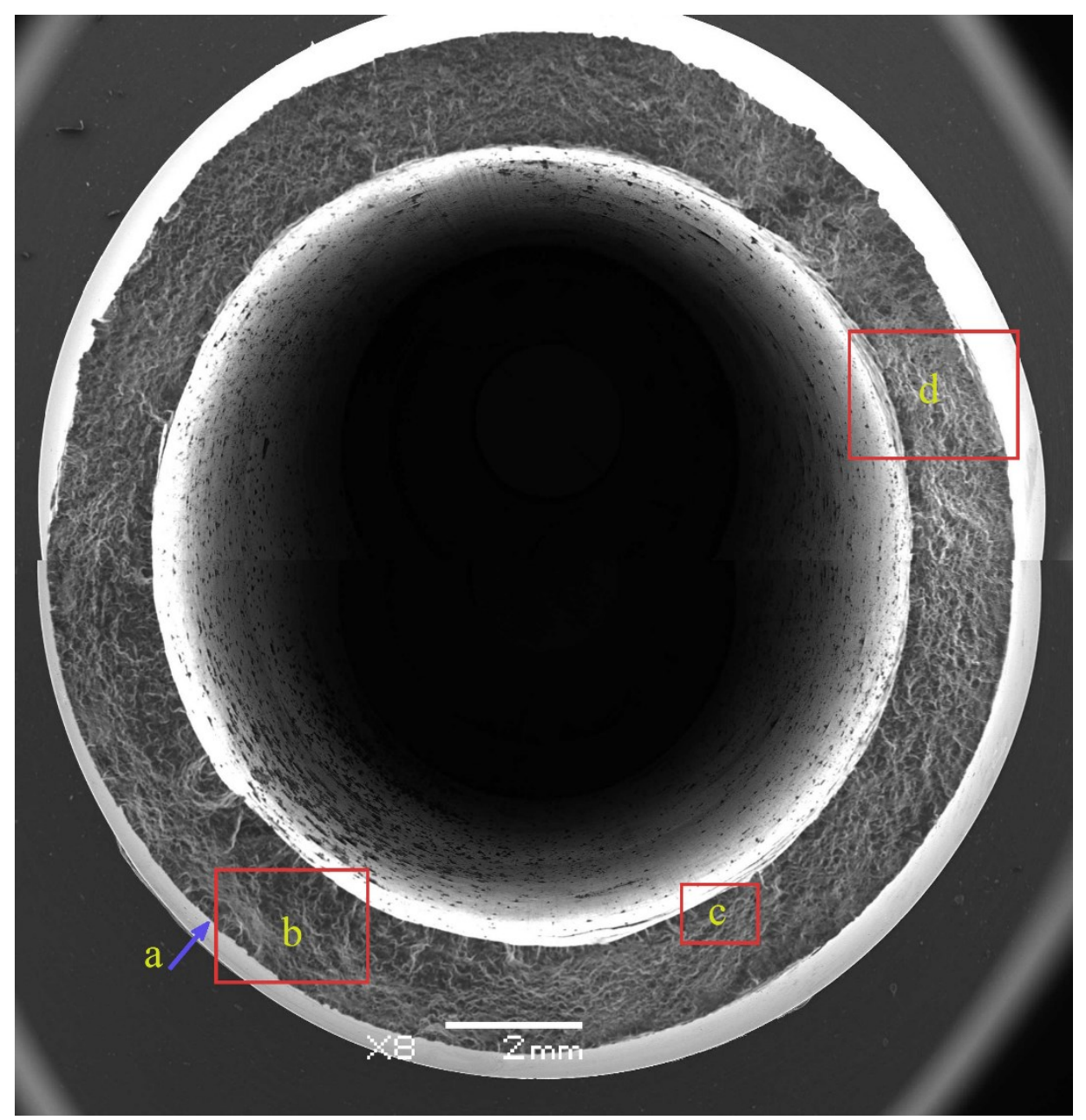

Fig. 5 SEM image of specimen's fatigue fracture: a) fragment where the onset of coalescence of small crack was identified by replication, b) the fragment on which the longest propagating crack developed, c) another small cracks initiation site that linked with the main crack, d) overload zone 


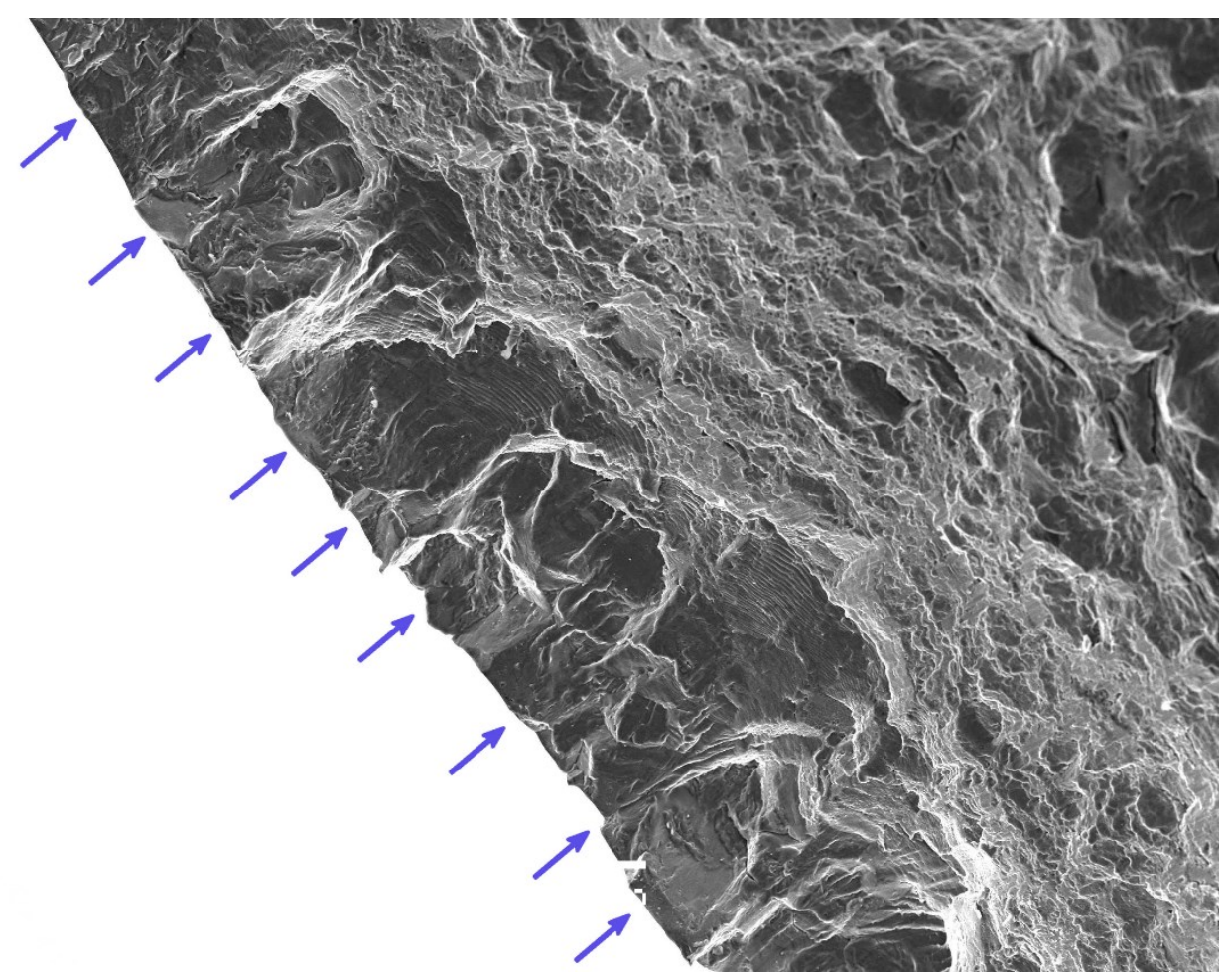

Fig. 6 Fatigue fracture's fragment (Fig. 5.a), in which the beginning of coalescence of small cracks, which further formed the main crack, was identified using replicas

When the specimen is tilted in the microscope's grip, the side surface of the specimen can also be observed (Fig. 7), and the other cracks, that did not link with the main crack. The size of these cracks is the same as observed on the replicas. The origin of this particular small crack is in the grain, which (due to machining) was almost completely removed. Therefore, it had more degrees of freedom which resulted in the initiation of crack [16]. On the fracture surface some inclusion can be seen. Using the EDS analysis it was detected that they contain $\mathrm{Al}, \mathrm{Fe}$ and $\mathrm{Si}$. Most likely, they are AlFeSi precipitations identified in other research regarding this alloy $[17,18]$. In Fig. 7.b, the magnified initiation site is presented (blue arrow). AlFeSi precipitations (red arrows) did not have any visible effect in the first stage. However, when the first striations appeared (green arrow), indicating the change in crack development mechanism, some perturbations around the precipitations can be seen. 


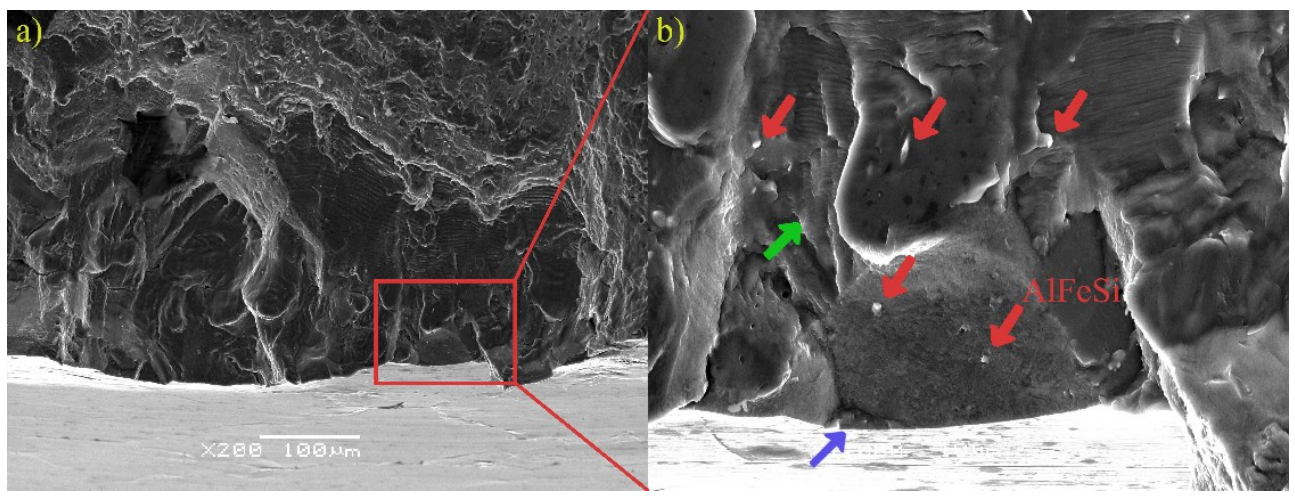

Fig. 7 Fatigue fracture's fragment presented previously in Fig. 6, after the specimen was tilted; side specimen's surface can be seen

The biggest, and probably the longest propagating crack, formed due to coalescence of small cracks present on the inner specimen's surface (Fig. 8). The blue arrows point the small cracks' origins, which are both on the inner and outer specimen's surface. It is not surprising for the axial loading, since the stress is the same in the whole cross section.

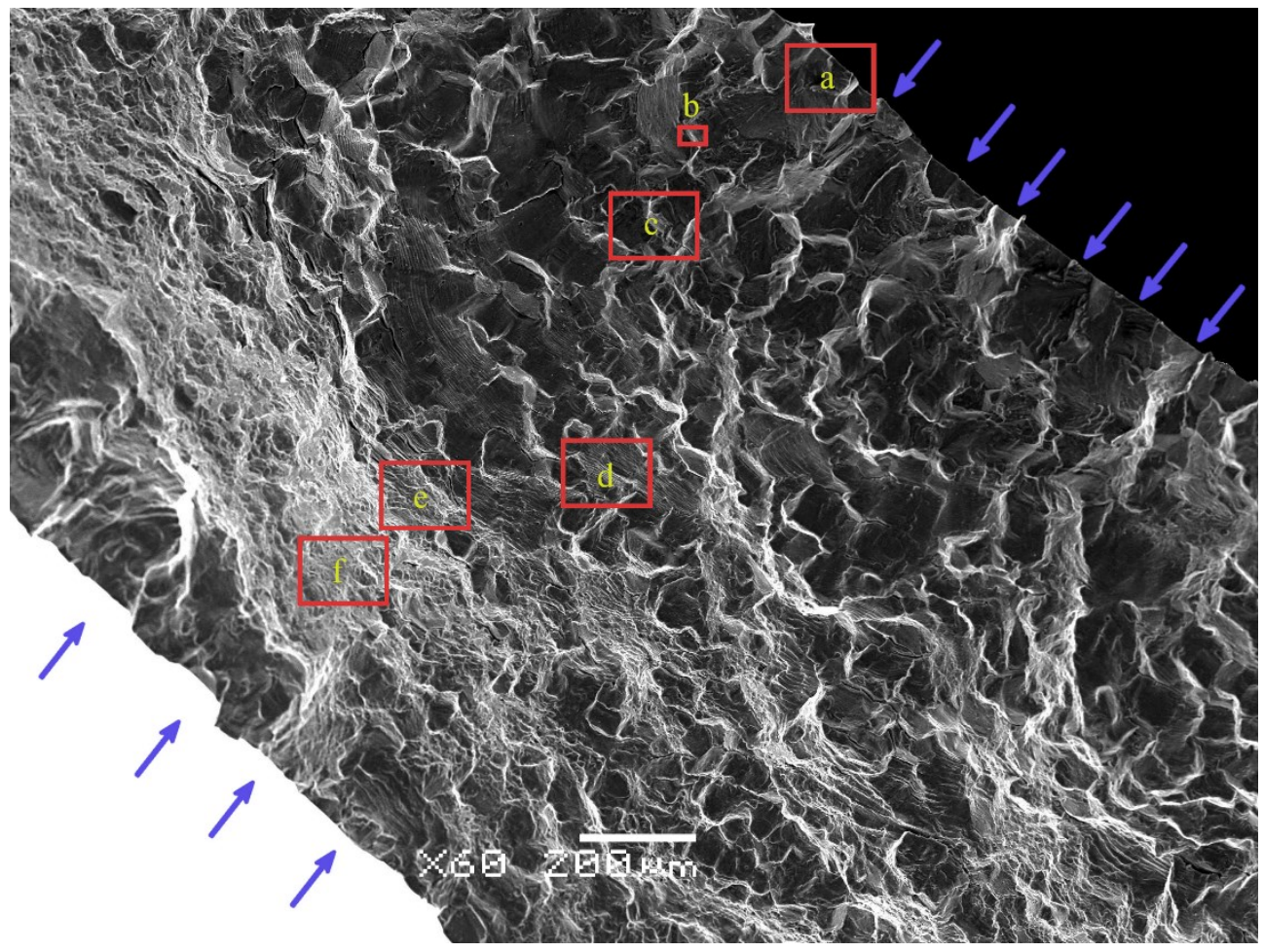

Fig. 8 Fatigue fracture's fragment (Fig. 5.b), in which the crack formed by the coalescence of small cracks on the inner surface of specimen, is visible. The marks regard the magnifications presented in Fig. 9

The first stage of fatigue crack development was the initiation and development of small cracks (Fig. 9.a). In the small cracks' initiation area, the fracture is brittle and forms the flat surfaces, on which the mutual influence of neighboring cracks was not observed. The small crack grew this way through approximately three grains, and then linked to form the common 
front, which propagated into the specimen's material. The first striations can be observed at a distance of approximately $0.2 \mathrm{~mm}$ from the specimen's surface (Fig. 9.b). They can be noted using higher magnifications. The rate of the crack growth increased with the increment of the crack's size, as evidenced by the increasing distances between the striations (Fig. 9.c). In Fig. 9.d, apart from the increasing size of the striations, there are also visible numerous secondary cracks, indicated by yellow arrows. Fig. 9.e shows a fragment of the fracture where it is still possible to recognize the direction of the crack growth, but it became impossible to distinguish the striations. In Fig. 9.f, the local instantaneous zone is observed, i.e. the fracture fragment where the cracks initiated on the inner and outer surfaces linked. There are many voids with the features of ductile fracture. Based on the replication it is known, that this fragment formed in the last 40 cycles of fatigue life. On a macroscopic scale, the major crack propagated from the location indicated by the blue arrow in Fig. 10.a, along the circumference to the instantaneous zone. But when magnifying such a fracture fragment (Fig. 10.b), it is observed that nothing indicates such a direction of crack propagation. Small cracks, linked by a coalescence mechanism, propagated in the direction from the inner and outer surfaces to the center of the specimen's cross section.

Fig. 11.a shows a fragment of the instantaneous fracture zone which has the features of a ductile fracture. There is a visible narrowing of the specimen's wall thickness and numerous voids, which indicate a very high deformation. Under magnification (Fig. 11.b, Fig. 11.c), larger transgranular fracture voids that nucleated around the AlFeSi precipitations, and smaller intergranular fracture voids can be distinguished. 


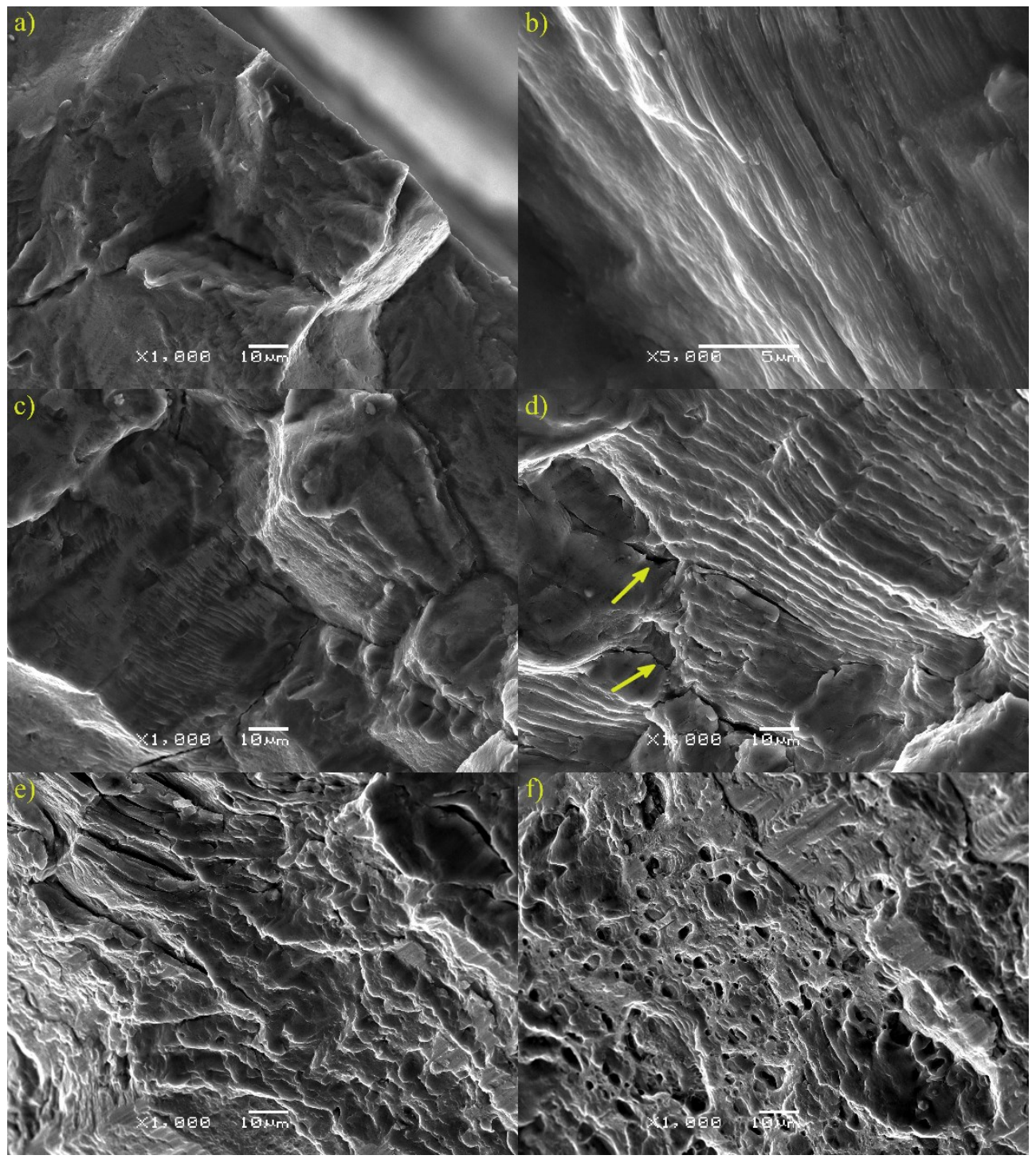

Fig. 9 Magnification of successive fracture fragments shown in Fig. 8. a) initiation of small cracks, b), c), d) propagation with the striations, e, f) rapid growth of the main crack 


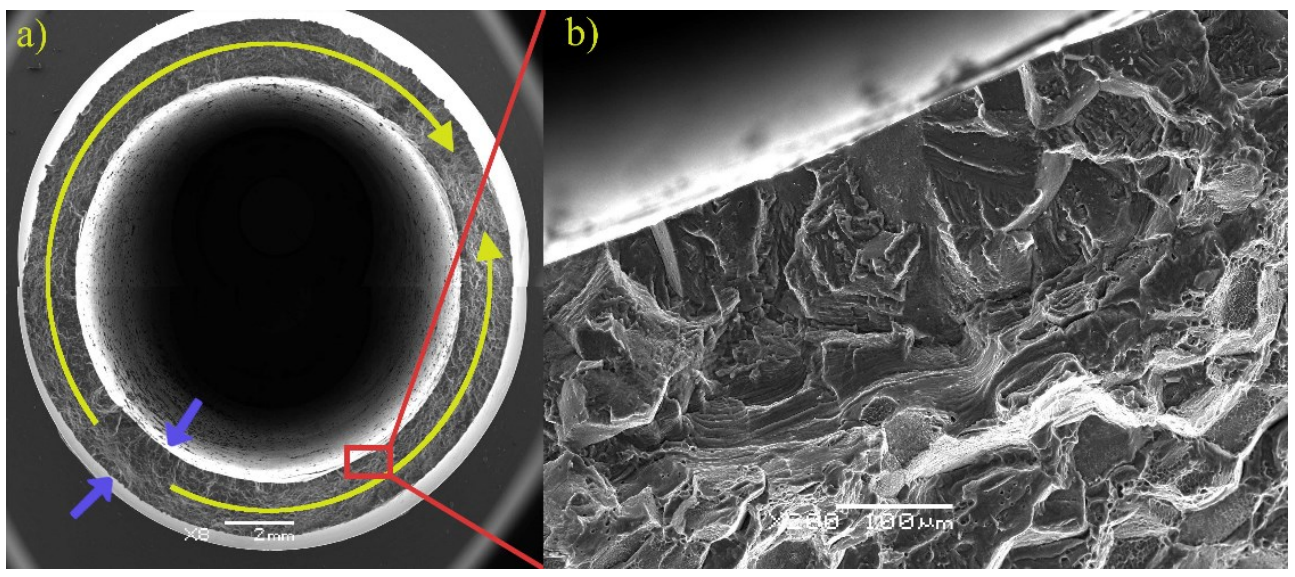

Fig. 10 The coalescence of small cracks during the main crack propagation. a) a schematic representation of the main crack propagation in the last 40 fatigue life cycles, b) coalescence of small cracks included in the main crack 


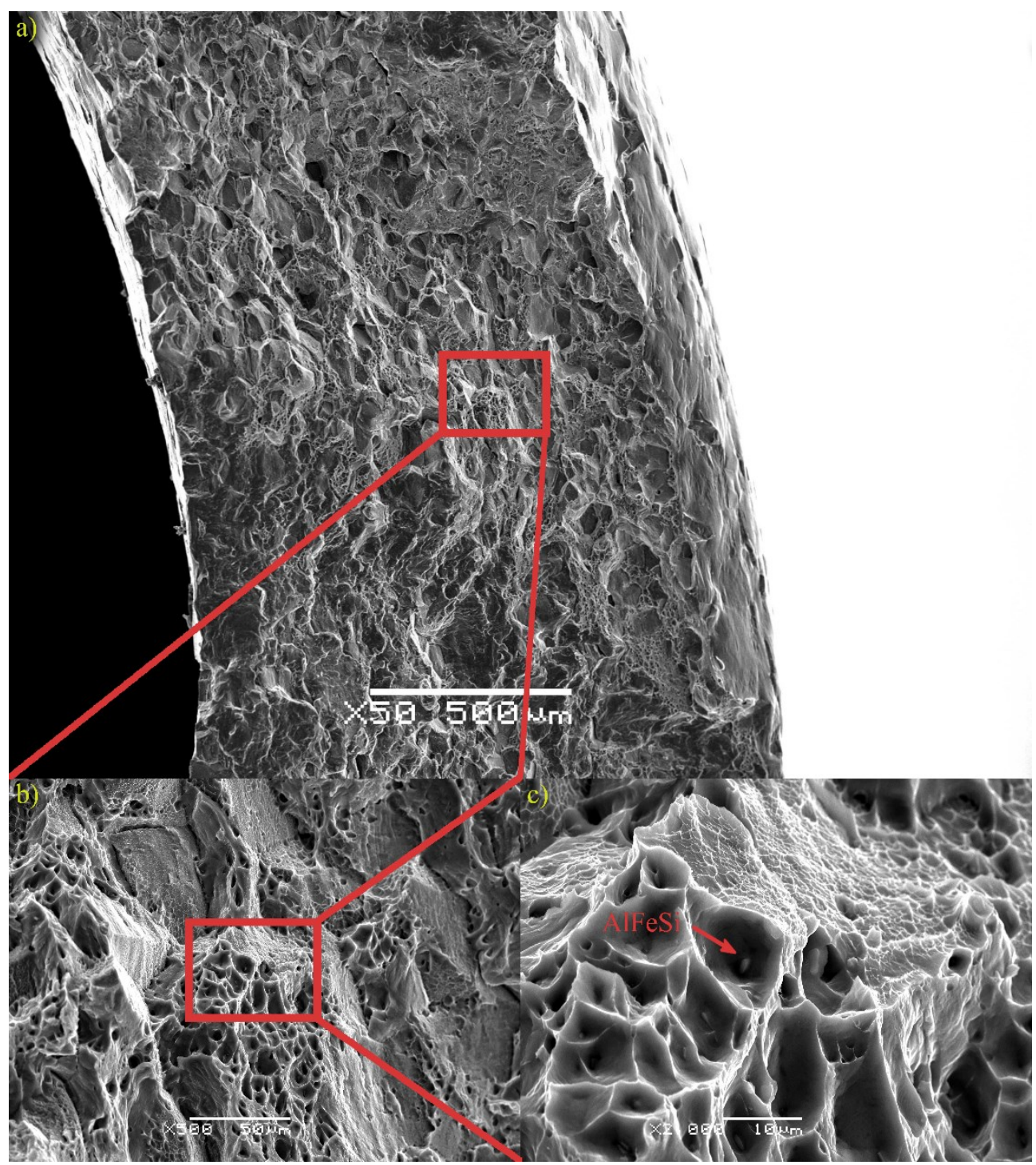

Fig. 11 Fragment of the instantaneous fracture zone shown in Fig. 5.d. Figures b) and c) are the further magnifications of this shot

\section{Conclusions}

The research confirmed the coalescence of small cracks, and at the same time showed that the cracks propagated towards the center of the specimen's cross-section. Using surface replication technique, it was observed that the crack propagation stage was a relatively small part of the fatigue life of the specimen. The main crack propagation proceeds from the inner and outer surfaces of the sample towards the center of the cross-section, and not from one origin to the instantaneous fracture zone. Ductile fracture with voids and narrowing is observed in the instantaneous fracture zone.

The presence of AlFeSi precipitates has a distinctly different impact on the various stages of fatigue crack development. There was no noticeable effect on the initiation and 
propagation of small cracks. At the propagation stage, in which striations are visible, these precipitations had little effect on the development of the crack. A very clear effect can be noticed in the instantaneous fracture zone of the specimen, in which they became the nucleus of voids, but from the point of view of the entire fatigue process, this stage is of little importance.

The conducted research shows that the vast majority of the specimen's fatigue life is spent to the formation of small cracks, which initiate as a result of the shear mechanism. This explains the results of the previous analyzes of fatigue life prediction methods. They showed that the application of the fatigue damage parameter, based on the maximum shear strain, resulted in the most accurate estimation of the fatigue life [14].

\section{References}

1. N. Shamsaei and A. Fatemi, Int. J. Fatigue 58, 126 (2014)

2. K. S. Chan and J. Lankford, Acta Metall. 36, 193 (1988)

3. R. Molaei, A. Fatemi, and N. Phan, Int. J. Fatigue 117, 352 (2018)

4. W. Zhang and R. Akid, Fatigue Fract. Eng. Mater. Struct. 20, 547 (1997)

5. N. Gao, M. W. Brown, K. J. Miller, and P. A. S. Reed, Int. J. Fatigue 29, 565 (2007)

6. C. T. Hua and D. F. Socie, Fatigue Fract. Eng. Mater. Struct. 8, 101 (1985)

7. Y. Z. Wang, J. D. Atkinson, R. Akid, and R. N. Parkins, Fatigue Fract. Eng. Mater. Struct. 19, 51 (1996)

8. J. Szusta and A. Seweryn, Int. J. Fatigue 33, 255 (2011)

9. T. Itoh and T. Yang, Int. J. Fatigue 33, 1025 (2011)

10. K. Walat, M. Kurek, P. Ogonowski, and T. Łagoda, Int. J. Fatigue 37, 100 (2012)

11. C. Cauthen, K. V. Anderson, D. Z. Avery, A. Baker, C. J. Williamson, S. R. Daniewicz, and J. B. Jordon, Int. J. Fatigue 140, 105790 (2020)

12. Ł. Pejkowski and D. Skibicki, Int. J. Fatigue 128, (2019)

13. D. Skibicki and Ł. Pejkowski, Int. J. Fatigue 123, 66 (2019)

14. Ł. Pejkowski and J. Seyda, Int. J. Fatigue 142, 105904 (2021)

15. J. Seyda, L. Pejkowski, and D. Skibicki, Procedia Struct. Integr. 28, 1458 (2020)

16. S.-T. Tu and X.-C. Zhang, Ref. Modul. Mater. Sci. Mater. Eng. (2016)

17. L. Aydi, M. Khlif, C. Bradai, S. Spigarelli, M. Cabibbo, and M. El Mehtedi, Mater. Today Proc. 2, 4890 (2015)

18. S. K. Panigrahi, R. Jayaganthan, and V. Pancholi, Mater. Des. 30, 1894 (2009) 